\title{
Spinoza on Ingenium and Exemplarity: Some Consequences for Educational Theory
}

\author{
Johan Dahlbeck ${ }^{1}$ (i) \\ Published online: 18 July 2020 \\ (c) The Author(s) 2020
}

\begin{abstract}
This article turns to the neglected pedagogical concept of ingenium in order to address some shortcomings of the admiration-emulation model of Linda Zabzebski's influential exemplarist moral theory. I will start by introducing the problem of the admiration-emulation model by way of a fictional example. I will then briefly outline the concept of ingenium such as it appears in a Renaissance context, looking particularly at the pedagogical writings of Juan Luis Vives (1492/3-1540). This will set the stage for the next part, looking at how early modern philosopher Benedict Spinoza (1632-1677) adopts a Vivesian notion of ingenium, adjusting it so as to fit into the setting of his political theory. Next, I will turn to Spinoza's use of the concept of ingenium in relation to his portrayal of exemplary persons, offering a pedagogical model of moral exemplarism that can counter some of the perceived problems of the admiration-emulation model as it highlights the necessary fallibility of efficient exemplars as well as acknowledges the socio-political dimension of emotions. Finally, I will lay out some preliminary consequences for educational theory, hoping to offer a way of reconciling moral exemplarism with a more realistic pedagogical and psychological framework.
\end{abstract}

Keywords Ingenium $\cdot$ Exemplarity $\cdot$ Spinoza $\cdot$ Vives $\cdot$ Admiration-emulation

\section{Introduction}

The purpose of this article is twofold. First, it aims to investigate the underexplored connection between recent neo-Aristotelian exemplarist approaches and Modern work in the philosophy of education. Second, it aims to introduce the pedagogical concept of ingenium as a way of shifting from the standard conceptual framework of moral exemplarism (focusing on the relation between novice and the exemplary person or narrative to be admired and emulated) to an approach more focused on conceptualizing the dynamic relationship between teachers and novices and the content of education. In contemporary moral exemplarist studies, focus is generally placed on identifying admirable exemplars (through narratives) that a young person may seek to emulate in order to become a moral person. From a

Johan Dahlbeck

johan.dahlbeck@mau.se

1 Faculty of Education and Society, Malmö University, Malmö, Sweden 
pedagogical point of view, however, this approach tends to underestimate the important role of the teacher as both an exemplary person-displaying pedagogical and ethical exemplarity through his or her behavior-and as the one offering an array of exemplary things and ideas for students to study-displaying didactical exemplarity (see Korsgaard 2019). The pedagogical concept of ingenium is particularly interesting as it allows for a focused discussion of what makes this relation-between teacher, student, and content-work pedagogically. This indicates a pedagogical dimension missing in mainstream exemplarist studies, a dimension that is pedagogical insofar as it highlights what is known as the pedagogical triangle, connecting the teacher to both student and content (see Friesen and Osguthorpe 2018).

While influential models of neo-Aristotelian exemplarism tend to focus on the relation between the emotion of admiration and the act of seeking to attain the admirable (see Zagzebski 2015, 2017), there are some glaring gaps in this set-up that seem to result from overlooking the sociability of emotions and the relational nature of human autonomy. This is where the concept of ingenium may help us appreciate the complexity and reciprocity of the pedagogical relation as a relation that balances between pedagogical and didactical exemplarity and between understanding someone's affective make-up and influencing that person in a direction deemed to be pedagogically and ethically valuable for them. As such, focusing on the ingenium of teachers and students can help us paint a more realistic and dynamic picture of how exemplarism functions in pedagogical situations, where the teacher is tasked with something far more challenging than simply pointing students in the general direction of admirable exemplars. A pedagogical situation is one where the relations between teacher, student, and content are all attended to so as to be jointly directed at the ethical flourishing of the student.

In what follows I will begin by offering a brief fictional example intended to illustrate the inherent limitations of the admiration-emulation model often relied on in contemporary moral exemplarism. Having indicated some shortcomings of the admiration-emulation model, I will then turn to the neglected pedagogical concept of ingenium in order to offer a strategy for discussing exemplarism in education in a way that looks beyond the narrowly conceived relation between novice and the narrative representing the admirable. While the focus in this paper is on explicating Spinoza's understanding and use of the concept of ingenium in his later political philosophy, it is important to begin by situating his use of the concept in the context of Renaissance pedagogy. For this reason, I will outline the concept of ingenium such as it appears in the pedagogical writings of Juan Luis Vives (1492/3-1540). Vives offers a valuable pedagogical insight insofar as he indicates the necessity of teachers properly understanding the temperaments of their students in order to be able to influence them through education. As such, Vives places the relationship between teachers and students firmly in the center of the pedagogical set-up in a way that frames moral exemplarism and that renders this relationship, in itself, exemplary.

This will set the stage for the next part, looking at how early modern philosopher Benedict Spinoza (1632-1677) adopts a Vivesian notion of ingenium, revising and adjusting it so as to fit into the setting of his political theory. This involves conceiving of ingenium in a more dynamic and reciprocal manner than Vives would have it. It also means shifting the focus from how the teacher can exploit the students' dispositions in order to willfully influence their behavior, to understanding pedagogical relations and adjusting pedagogical interventions in light of the fundamentally social and relational nature of human emotions. Next, I will turn to Spinoza's use of the concept of ingenium in relation to his portrayal of exemplary persons, offering a pedagogical reinterpretation of his political model of moral exemplarism. It is argued that this pedagogical reinterpretation can counter some of the perceived problems of the admiration-emulation model as it highlights the necessary 
fallibility of efficient exemplars. While Spinoza conceives of exemplary narratives in a political context, I argue that the way he utilizes insights from Vives (and Renaissance pedagogy) and marries them with a naturalistic ${ }^{1}$ psychological framework, has interesting consequences for contemporary educational theory.

In this way, while a substantial part of this article concerns an investigation into the Modern history of the idea of ingenium, the purpose for this investigation is ultimately to offer a persuasive reinterpretation of a neglected pedagogical concept that can help us look beyond the constraints of the admiration-emulation model and offer a more productive way of reconciling moral exemplarism with a realistic psychological and pedagogical framework. It is deemed more realistic insofar as it is more relationally conceived and insofar as it highlights the fundamentally social and political dimensions of becoming a moral person.

\section{Being Good or Being Real: The Case of Richard Fountain and the Problem of the Admiration-Emulation Model}

The first few chapters of Simon Raven's novel Doctors Wear Scarlet (2019[1960]) are dedicated to a detailed description of the character Richard Fountain. Richard Fountain, described by his friend Anthony Seymour (who recollects his friend at the request of Inspector John Tyrrel of the Metropolitan Police), is a Cambridge scholar who is portrayed as being courageous, modest, always willing to help others, and as a man with great integrity and good sense (Raven 2019[1960], 18-19). Yet there is something odd about Richard Fountain. For all his morally admirable character traits there is something not quite right about him. Besides a couple of minor incidents, one of which reveals Richard Fountain's ability to resort to violence when provoked (albeit clearly in a situation where this is morally defensible), the first closer look at this difficult-to-pin-down oddness concerns his tarnished reputation as an army officer.

'Yes ... I can see he might have done well in the Army. Competent, intelligent, good physical specimen. Fully prepared to tell others what to do - and to take his own share in it. Brave. And with a very suitable outlet for this violence you speak of. Not popular with his men though?' said Tyrrel shrewdly.

'No, too good to be true. To be popular with his men an officer must be fallible.' (Raven 2019[1960], 47)

The problem with Richard Fountain is that he is perceived as too good. As such, he offers no stable point of reference that can be of practical use for the people who admire him.

\footnotetext{
1 In this article, when I use the terms nature and natural it should be understood in the context of Spinoza's fundamentally naturalistic tenet stating that: 'The laws and rules of nature, according to which all things happen, and change from one form to another, are always and everywhere the same. So the way of understanding the nature of anything, of whatever kind, must also be the same, viz. through the universal laws of nature' (E3pref). From this point of view, human psychology and human emotions are just as natural as anything else in the natural world, and the proper way to understand them is to subject them to the same kind of investigation we would any other phenomenon. Spinoza continues: 'Therefore I shall treat the nature and powers of the Affects, and the power of the Mind over them, by the same Method by which, in the preceding parts, I treated God and the Mind, and I shall consider human actions and appetites just as if it were a Question of lines, planes, and bodies' (E3pref). For an insightful take on the various ramifications of Spinoza's naturalistic psychology see Michael Della Rocca's (1995) 'Spinoza's metaphysical psychology.'.
} 
He is simply not attuned to the people he is supposed to be the leader of. Being too good makes him seem less real, and seeming less real means that he falls out of touch with the people who would admire him for his otherwise exemplary character.

The case of Richard Fountain speaks to a problem inherent to the admiration-emulation model of Zagzebski's (2017) influential exemplarist moral theory. On Zagzebski's account, moral exemplarism is largely motored by the emotion of admiration. The general idea is that when we observe someone whom we perceive to display truly exemplary behavior, this triggers our admiration, and that our admiration, in turn, triggers our desire to emulate the behavior of the moral exemplar. Zagzebski stipulates that 'under appropriate conditions, admiration for a person moves us to emulate the admired person in the respect in which the person is admired' (2017, 33). By identifying and admiring exemplary behavior, then, we are assumed to begin a transformation of our own behavior in the same direction. And by experiencing the emotion of admiration, we are assumed to have identified something admirable, and hence, something worthy of emulation. As has been pointed out recently by Szutta (2019), however, the central role assigned to admiration by Zagzebski is questionable. This is so as admiration is inherently unreliable in the sense that behaviors we tend to admire may not turn out to be morally exemplary at all. In addition, the reliability of admiration appears to presume an already existing level of practical wisdom informing us of which behaviors to identify as admirable to begin with.

Accordingly, there is a clear danger of relying on admiration in an educational context. Part of the danger is that we may come to admire behavior that is not morally exemplary, and we may admire people who are therefore not moral exemplars. A corollary to this danger is that in order to be able to rely on our admiration we need to already have a sufficient degree of 'knowledge and understanding of good and virtues' (Szutta 2019, 286), which seems to be a questionable starting point for education. The flip side of this corollary is that if we lack the necessary moral attitudes and dispositions to begin with, we may not admire moral exemplars at all (even if we are made aware of their exemplary character by a teacher let's say). We may instead, as in the case of Richard Fountain, simply find exemplary persons too good and infallible in a way that makes them seem alien and inaccessible. ${ }^{2}$ As Szutta remarks, '[t]he key to securing an effective motivation to emulate moral exemplars is their attainability and relevance to those who are to emulate them' (Szutta 2019, 289). Richard Fountain is precisely not perceived as attainable (alternatively, he is simply taken to reflect different values than those of his men), and therefore he is also not relevant as a moral exemplar. To state it more precisely, the case of Richard Fountain and the challenge posed by Szutta show how exemplarity and admiration come apart in both directions. That is, the case of Richard Fountain illustrates how a person can be exemplary without being admired and Szutta's challenge indicates that a person can in fact come to admire the non-exemplary. ${ }^{3}$

Moral exemplars, on this account, need to be attuned to the particular sociocultural context of those agents striving to become more ethical in order for them to function accordingly. As Alkis Kotsonis has recently argued, the admiration-emulation model of

\footnotetext{
2 As Michel Croce has recently noted, the perceived inaccessibility of some moral exemplars (specifically saints) risks not only failing to enlist the admiration of students, but admiration may even give way to 'a negative emotion, namely discouragement, as soon as they realize how far away they are from the impressive deeds of the admired saints' $(2020,191)$.

3 I am indebted to Justin Steinberg (personal communication, April 30, 2020) for pointing out the subtle difference between Szutta's challenge and the challenge posed by the Richard Fountain case.
} 
Zagzebski's moral exemplarism 'does not consider the import and influence of prevailing socio-cultural norms and values on the agents' identification of "the admirable", (2020, 225), and therefore it misses the crucial aspect of accounting properly for the social setting impacting the affective composition of the agent. This is important, as the identification process by which admiration functions is 'largely affected by several features and characteristics of the agent' (ibid.). Taking the agent's affective composition or character (as well as the surrounding social setting) into account, then, would be a necessary starting point for moral exemplarism insofar as moral exemplarism is proposed to play a productive role in the educational transformation and ethical improvement of people. This would mean acknowledging that admiration is a largely social emotion, much more sensitive to the influence of sociocultural norms and values than the admiration-emulation modelfocusing narrowly on the individual experiencing admiration-would have it.

The next section of this article serves two interrelated purposes. First, it serves to introduce the pedagogical concept of ingenium via the work of early modern humanist Juan Luis Vives. What is particularly important here is the focus Vives places on properly understanding the teacher-student relation and on appreciating the exemplary function of the teacher (and not just the subject matter studied or the thing/idea pointed to by the teacher). Second, it serves as a prelude of sorts to the subsequent parts on Spinoza, as Vives figures as a pedagogical and philosophical precursor to Spinoza in his work on the importance of accounting for the ingenium of a people in a political context (see Steinberg 2018). In order to properly gauge Spinoza's contribution to educational theory (by translating his psychological and political insights into pedagogical insights), then, we must first investigate the legacy of Vives' pedagogical ideas for Spinoza's political philosophy.

\section{Reconnecting with a Lost Pedagogical Tradition: Diagnosing and Accounting for the Student's Ingenium and Understanding the Role of the Teacher Qua Exemplar}

In an early modern pedagogical setting, the concept of ingenium is typically contrasted with, and intimately related to, the acquisition of a virtuous character. Ingenium is the raw material (the innate talent or natural predisposition) from which a virtuous character must be arduously carved. Virtue will not come easily however, as a person's ingenium will not yield readily to the instruments and skills of even the most competent artisan. ${ }^{4}$ Historian of ideas Andreas Hellerstedt explains the complex relation between virtue and ingenium:

Virtue was those character traits or dispositions which we acquire, and thus represent our potential for improvement, or even an ideal humanity. It is the optimistic side of seventeenth century anthropology. Ingenium, on the other hand, was that which we cannot change, our natural predisposition. In that sense it was more negative, as it represented the limitations of mankind, and of the individual. (Hellerstedt 2019, 78)

\footnotetext{
4 There are variations regarding to what extent the ingenium of a person was believed to be malleable. Vives' account, which will be the focus of the first part of this article, tends toward an understanding where a person's ingenium can in fact be shaped through habituation and education. As Steinberg notes, 'Vives stresses the malleability of one's physiology and, in turn, ingenium, through habituation' $(2020,160)$. The relation Vives sets up between the formation of the body and of ingenium is something that we will have cause to return to.
} 
In order to properly gauge the adequate means by which to cultivate virtue, then, the student's ingenium would need to be carefully assessed and taken into account for pedagogy to become truly efficient. Hellerstedt likens the process to that of the medical doctor diagnosing the patient before giving proper treatment:

The teacher is advised to first examine the "disease" and its causes before he administers his medication, just like a physician: the teacher should examine the ingenia of his students and entice the power of their talent before he begins teaching them. (Hellerstedt 2019, 80)

One of the more prominent advocators of grounding pedagogy in a careful diagnosis of the ingenia of students in the early modern period is Juan Luis Vives. In his De Tradendis Disciplinis (1913), Vives discusses this in some detail. The parallel to medical science and to the treatment of physical ailments, identified by Hellerstedt above, is notably present in Vives' account:

And all these things are judged by each person according to his own intellect; for some things suit some minds, and some things others, just as certain foods suit certain palates and stomachs. For there is no knowledge so good that we cannot corrupt it, just as there is no food so healthy that it cannot become unhealthy, if it gets infected with disease. (De Tradendis $1.4,33)^{5}$

Diagnosing the mental condition of the student, the teacher is cast in the role of the equivalent to a skilled physician, working meticulously on assessing and treating the minds of students (rather than the bodies of the sick). ${ }^{6}$ The challenge facing the teacher is much the same as the challenge facing the physician. Just as each individual body requires a slightly different approach, so each mind requires its individually calibrated treatment to fit with its temperament:

Different subjects of study require, in each case, a distinct type of natural mental ability for its successful pursuance. It is possible, however, to obtain a judgment as to which studies a particular person would wisely refrain from undertaking. Just as a skillful medical man can pronounce with regard to the bodies of men after he has had them under his examination, so the man of practical wisdom (vir prudens) can form a judgment as to the special excellencies of mind, judgment and learning of a particular person, if he be called in, to act in this so important a function. (De Tradendis 1.4, 33-34)

While a virtuous character can be made to manifest in the inhospitable terrain of a person's natural predisposition, the terrain itself - the ingenium-cannot be completely transformed (but only refined through habituation and education). Instead, it must be disclosed, accepted and prepared for a pedagogical intervention, and so ' $\mathrm{t}$ ] $\mathrm{o}$ this end we must partly learn and accept what has been handed down to us, and partly think it out for ourselves and

\footnotetext{
${ }^{5}$ References to De Tradendis Disciplinis (De Tradendis) are to Book, Chapter and page number of Vives (1913).

${ }^{6}$ Much like the adept physician can be indispensable for alerting the patient to the best suited cure for his or her ailment, the teacher's careful examination of the student's ingenium is construed by Vives as being indispensable for the success of education. As Hidalgo-Serna puts it: 'Hence the success or failure of intellectual cultivation or education which young minds will experience depends on how correct or faulty the teacher's psychological-pedagogical examination of ingenium is' $(1983,234)$.
} 
learn it by practicing it' (De Tradendis $1.4,36$ ). While education can influence the ingenium, it needs to pay close attention to its particularities so as to be suitably adapted to the natural disposition of the student's mind. Accordingly, Vives concludes that '[s]ome minds are sensible, sober and temperate; others insane and furious, and this either habitually or at intervals. Some are gentle, others fierce and eager; some even are of an unbridled nature' (De Tradendis 2.3, 80). Making things more difficult, a person's disposition is prone to changes over time and in response to the surrounding environment, much like a body reacts in different ways to the different foods it ingests:

Variations of mind arise from the different nature of each person, i.e. of the constitution and temperament of their bodies. The consequence is, that a man one moment may be great and keen-witted, and the next moment may no longer remain so. (De Tradendis 2.3, 76-77)

The variations of students' ingenia, and the many changes of any one student's disposition in response to varying external circumstances, makes the teacher's task exceedingly difficult. As such, Vives recognizes that not only do the teacher need to be knowledgeable in the subjects taught, but the teacher must also be a certain kind of person so as to appear as an exemplar for the student. A good teacher must behave in a way that corresponds with the teaching offered and so, on Vives' account, '[t]eaching with which the life does not correspond is harmful and disgraceful' (De Tradendis 2.1, 59). In order to ensure that the teacher's character is suitably aligned with his/her teaching, the teacher's own ingenium needs to be mapped out and understood. Self-examination thereby becomes an integral part of teaching, much like the careful examination of the students' character and ingenium is a precondition for successful education. ${ }^{7}$

Interestingly, this indicates the exemplary role of the teacher in a way that goes to illustrate how the practices of self-examination and of properly diagnosing the ingenium of the students function as two preconditions for establishing a pedagogical relation where the teacher becomes exemplary in two parallel yet distinct senses. The teacher is exemplary in a pedagogical sense insofar as he or she lives in a way that corresponds with his or her teachings (that is, he or she displays an ethical way of life that corresponds with the lessons taught while also being suitably adjusted to the ingenia of the students), and the teacher is exemplary in a didactical sense insofar as he or she can identify things and ideas that will function as valuable representations of the world given the students' ingenia. Balancing between pedagogical and didactical exemplarism (see Korsgaard 2019) requires a teacher that is exemplary insofar as he or she has carried out a degree of self-examination sufficient for engaging in a pedagogical relation that balances successfully between accommodating students' ingenia and influencing them to strive to become more ethical (through a combination of pedagogical and didactical exemplarism).

It is important to note that the parallels Vives draws to physiology are not strictly metaphorical, however. Indeed, the ingenium of a person is believed to be closely related to the constitution of the body, and so changes in the body entail changes in one's disposition and

\footnotetext{
7 Steinberg talks about the two-fold role of ingenium in the humanist pedagogy of Vives as a dynamic and reciprocal process. On the one hand, the teacher must endeavor to assess the ingenium of the student, but on the other hand, 'the ingenium of the teacher enabled him to discover effective modes of instruction' (2020, 159). I take this to mean that while great importance is placed on the teacher's ability to correctly diagnose the ingenium of the student, a precondition for the teacher being able to do this is that the teacher's own ingenium is made to resonate with the student's. This is an important aspect that is made more pronounced in Spinoza's adoption of the concept.
} 
character. A person's ingenium, Vives speculates, is rooted in the constitution of the body, which means that it is susceptible to both training and habit (much like the body is). To the extent that a teacher succeeds in adapting a student's education to his or her ingenium, the powers of the mind can be productively put to use in the striving for virtue. As such:

Vives made two basic assumptions [about ingenium]: first, that the physiological features of the individual are a decisive ingredient of his temperament and character; second, that temperamental dispositions are of paramount importance in regulating man's intellectual powers. (Noreña 1970, 268)

The idea that the natural predisposition of students and teacher matters for pedagogy is of course still present in contemporary educational theory, even if it is hardly ever discussed in terms of ingenium/ingenia. ${ }^{8}$ For example, in his discussions on the relation between role and person in teaching (and of the importance of infusing the role with an actual person), David T. Hansen especially notes the demand on teachers' moral sensibility. As such, he is highlighting the importance of 'the disposition, the knowledge, and the practical wisdom that an individual brings to life in the role of teacher' $(2001,39)$. Rather than focusing solely on the teacher being attuned to the character of the students, however, Hansen stresses the importance of the teacher continuously 'pondering who one is in relation to students' (11). This indicates that the relative proximity between teacher and student (or between moral exemplar and agent) plays an important role for the success of the pedagogical transformation towards a more ethical life. In addition, it allows us a glimpse of a contemporary version of the teacher qua exemplar insofar as it echoes Vives' insight of the importance of a teacher being willing to submit to self-examination in order to be able to engage in a dynamic pedagogical relation with students. This invites a broader conception of exemplarism than the one offered by Zagzebski's admiration-emulation model where the relation being focused on concerns that between the novice and the admired exemplar. The teacher, in Zagzebski's model, is simply a person pointing to an existing exemplar; it is the exemplar doing the actual work in term of ethical transformation. The teacher's exemplarity, in a Vivesian sense, is visible both in the sense that the teacher must be sufficiently attuned to the ingenia of the students in order to be able to influence them ethically, and in the sense that the teacher must be able to identify exemplary things and ideas that speak to the ingenia of the students. This understanding of exemplarism is broad as it points in two directions simultaneously, one pedagogical and the other didactical. Morten T. Korsgaard describes these two complementary dimensions of exemplarism as follows:

The first way in which exemplarity works educationally is pedagogical and ethical, and concerns how personified exemplification plays a part in education, both in the form of narratives and in the way in which teachers themselves can function as exemplars. I will use the term pedagogical exemplarity for this dimension of teachers work. The second way exemplarity works educationally is in the form of examples

\footnotetext{
${ }^{8}$ Hidalgo-Serna notes this trend in a broader context, but as I take philosophy of education/educational theory to be part of a wider Humanistic tradition, I think it applies here as well. Hidalgo-Serna writes: 'There is a fundamental problem in philosophy and the Humanistic tradition that has not been dealt with sufficiently. The philosophical significance of ingenium is no more acknowledged today than in earlier times' (1983, 228). While Hidalgo-Serna's text is now a few decades old, there is no indications of any major changes as to his conclusion about the unfortunate neglect of ingenium. In the context of this article, I am less concerned with determining the more general appeal of ingenium as a pedagogical concept and more interested in discussing the educational consequences of Spinoza's use of the concept of ingenium.
} 
that are used to explicate or illuminate subject matter. In other words, this concerns finding the right examples or exemplary things to bring to the table in teaching. This dimension I will refer to as didactical exemplarity. (Korsgaard 2019, 271)

The exemplary teacher is thus no longer solely concerned with identifying morally exemplary narratives that may influence the behavior of admiring novices, but with setting up a dynamic pedagogical relation where the teacher inhabits the role of the exemplar, not only in the sense of being a moral exemplar to emulate, but also in the sense of finding useful examples that can to speak to the ingenia of students while also opening up their views to the world.

In a slightly different context, Jan Masschelein and Maarten Simons also notably stress the fact that not all teachers can be expected to appeal to all students in the same way. While they do not spell it out in these terms, I take it to imply that the natural predispositions of students and teachers are not always aligned and that the consequence of this is that schools need to offer a wide array of teachers with different dispositions capable of appealing to different students. They write:

A group of diverse, loving teachers increases the chance that a student will meet at least one teacher who stimulates his or her interest; loving teachers as well as school leaders are well aware that they cannot stimulate every student's interest and that being popular does not necessarily coincide with being inspiring. (Masschelein and Simons 2013, 127)

It seems to me that a precondition for teachers being able to successfully stimulate a particular student's interest (in a way that corresponds with the moral exemplar being able to appeal to the natural predisposition of the agent), is that the ingenia of students and teachers are sufficiently proximate to allow for a kind of moral communication where similar emotions and affects arise from similar circumstances. This aspect, however, is under-explored in contemporary educational theory and so it is called for to revisit, critically evaluate, and perhaps also update the lost pedagogical tradition of diagnosing and accounting for ingenium. ${ }^{9}$ The distinction indicated in the above quote between being popular and being admired seems important here. While popularity surely hinges on proximity insofar as to be popular requires some degree of relatability, it is perhaps less clear that admiration presupposes proximity in the same sense. Indeed, admiration may even require a certain distance between the admirer and the locus of admiration. ${ }^{10}$ The purpose

\footnotetext{
9 At this point, this may seem blatantly false insofar as most modern theories or methods of student-centered education are geared at adjusting the learning environment so as to meet the specific demands posed by the predisposition of the student. However, as I mean to show, there is a clear difference between adjusting education according to the expressed wants and needs of the student and stressing the importance of understanding the ingenia of students and teachers so as to identify what particular students truly need (but may not be aware of and therefore not explicitly want), and how a particular teacher may work to satisfy that need. Spinoza scholar LeBuffe (2010) calls this kind of teacher-figure 'the optimistic nutritionist', and it describes a person who is proficient at distinguishing the seemingly good from the truly good, and at learning to identify and strive for those things that are in agreement with one's ingenium while also being conceived in terms of sustainable (or true) rather than temporary goods. While LeBuffe does not focus on the educational implications of 'the optimistic nutritionist' (he does not explicitly conceive of 'the optimistic nutritionist' in terms of a teacher) I have attempted to do so in previous studies (see Dahlbeck 2016, 2017).

10 As Justin Steinberg has helpfully pointed out to me (personal communication, April 30, 2020) this might well figure into the case of Richard Fountain insofar as the problem may not be that he is not admired by his men, but that he is in fact not popular. While being popular and being admired is not the same thing, I propose that both qualities are importantly connected with how people are attuned to one another affectively. While being popular is perhaps of secondary interest for education, it appears important to investigate how
} 
of studying students' ingenia, then, is not to figure out a foolproof way of securing teacher popularity by maximizing the proximity of teacher and students, but to map out the affective compatibility between teacher and students so that moral communication is made possible to begin with.

When exploring the pedagogical promise of studying the configuration of different people's affective composition in a previous article (Dahlbeck and De Lucia Dahlbeck 2020), my co-author and I turned to the political theory of Spinoza as a valuable theoretical resource for addressing some perceived shortcoming of Zagzebski's exemplarist moral theory. Spinoza's use of the concept of ingenium is particularly enlightening as it clearly warns against the pedagogical and political dangers of disregarding a person's or a people's natural predisposition when seeking to influence and improve their behavior by way of exemplars. Before looking at some preliminary consequences for contemporary educational theory, I would therefore like to look closer at what Spinoza's political theory (set up against the background of his naturalistic psychology) can add to the pedagogical discussion of moral improvement via exemplars.

\section{Spinoza on the Ingenia of Individuals and Peoples}

According to Steinberg (2020), Spinoza's understanding of the concept of ingenium differs in some important aspects from the dominant understanding found in an early modern pedagogical context. ${ }^{11}$ First, it veers away from the connotation to innate genius and highlights instead the sociocultural and sociopolitical frameworks of a person's affective composition. A person's ingenium, for Spinoza, is less a question of innate talent (insofar as this is believed to exist independent of external influences) and more a question of a person's overall mentality or temperament ${ }^{12}$ (being always bound up with external affects and social emotions). A person's disposition, on Spinoza's account, is always in part a social question as emotions are always in part socially constituted. Second, while humanist pedagogues such as Vives focused almost exclusively on the importance of diagnosing the ingenium of the student (so that it may be manipulated to the benefit of ethical and pedagogical transformation), Spinoza's use of the concept points to a more fundamentally relational understanding. For Spinoza, the natural predispositions of teachers and students (or exemplar and agent) need to be gauged in relation to one another rather than treated as isolated or independent mental entities.

An interesting consequence of this, that we will return to in the next part of this article and in the final discussion, is that an exemplary teacher is only an efficient exemplar to the extent that he or she is properly attuned to the ingenium of the student. The teacher may not

\footnotetext{
Footnote 10 (continued)

moral communication is made possible (and impossible) by peoples' affective composition, being determined in turn by social factors that are beyond the control of the individual.

11 Steinberg notes that the use of the term ingenium is complicated by the fact that it has several possible meanings in an early modern context: 'It can denote wit, intelligence, cleverness, spirit, mentality, temper, and character, among other things. Ingenium was also closely linked to the concept of ingeniosus, conjuring up notions of inventiveness, resourcefulness, and even genius' (2020, 159).

12 In Curley's translation of Spinoza (1985a, b, 2016a, b) ingenium is sometimes translated as temperament and sometimes as mentality.
} 
be an exemplar in the strict sense of the admiration-emulation model outlined above, but rather in the sense of constantly striving to balance between living in a way that accords with his or her teachings (i.e. exhibiting exemplary behavior) and selecting examples and exemplary narratives that excite the imagination and that allow students to become better acquainted with the world they inhabit. There is of course still a sense in which the teacher may need to be judged admirable in order to be truly exemplary, but it is a kind of admirability that is always restricted by a sense of approachability. That is, if the teacher is no longer deemed approachable by the students, then the admirability displayed is no longer efficacious as it cannot offer a realistic or persuasive image of how to act morally from the point of view of the students' ingenia.

Spinoza shares with Vives, however, an understanding of the importance of carefully assessing the ingenium of the student or subject before working to improve his or her character. They also share the conviction that this process must be willingly participated in (which is why the student or subject must be able to identify with the ingenium of the teacher or leader) (Steinberg 2020,167). While Spinoza's context is that of political philosophy and ethics, his method corresponds to some extent with Vives' pedagogical ideas. This, in turn, is why it is useful to engage with Spinoza's application of the concept of ingenium in the context of educational theory.

Steinberg argues that Spinoza's political philosophy-being firmly grounded in his naturalistic account of human psychology-hinges in important ways on what he labels Spinoza's 'Principle of Accommodation' (2018, 115-117). The concept of ingenium is central for this thesis as a crucial aspect of efficient politics is taken to be that 'commands and teachings should be accommodated to the ingenia of affected parties, such that these commands and teachings elicit optimal (epistemic and affective) responses' (115). Accommodation, on this account, 'aims not merely at meeting people where they are, but to help reform their ingenia, so that their affective state is characterized more by hope and security than by fear' (Steinberg 2020, 167). A powerful way of connecting with people affectively - either in politics or in pedagogy - is through the use of collective narratives. By being able to identify narratives that speak to people's ingenia, a political leader or exemplar can draw on people's imagination to elicit their motivation to learn and act via the principle of accommodation. This indicates a different way of approaching the use of narratives from that of Zagzebski's admiration-emulation model however. Whereas for Zagzebski, narratives are tools allowing novices to get acquainted with an exemplar's deeds, for Spinoza, narratives are tools used by the exemplar to actively foster the motivation and imagination of the people.

In light of the above, one might legitimately wonder whether Spinoza makes any distinction at all between pedagogy and politics, and between political theory and social psychology. As Steinberg notes, the line Spinoza draws between pedagogy and politics is indeed blurred insofar as 'his account of the method and aims of politics resembles Renaissance humanist rhetorical approaches to pedagogy [...] so strongly that it is hardly an exaggeration [to] conclude that, for him, politics is education writ large' (Steinberg $2020,158)$. This is not to say that there is no such distinction to be made however. I believe that one may propose such a distinction while keeping in mind that (a) it must be carefully reconstructed from the broader picture of Spinoza's overall philosophical project (as Spinoza never wrote a treatise on education), and (b) that the close ties between social psychology, politics, and pedagogy in Spinoza are not accidental, but an integral part of his naturalistic conception of the ethical formation of human beings in society. If humans 
were naturally equipped for ethical flourishing on their own, they would not need laws and they would not need society to begin with (TTP 5 [18-22]). As they are not sufficiently equipped, however, they need powerful collective narratives that can help keep them together under the auspices of a peaceful commonwealth, capable of protecting them from one another and from various external threats. Education, then, is an effective way of uniting people through collective narratives while also ensuring that these narratives are not enflaming superstition and fear but rather working to promote peace and security. Peace and security, in turn, is necessary for the individual's striving for ethical flourishing. This is so as humans are naturally sociable and because cooperation is absolutely necessary for human flourishing. Indeed, for Spinoza, a stable social order is a precondition for the ethical well-being of the individual:

A social order is very useful, and even most necessary, not only for living securely from enemies, but also for doing many things more easily. For if men were not willing to give mutual assistance to one another, they would lack both skill and time to sustain and preserve themselves as far as possible. (TTP 5[18])

Education, from a Spinozistic point of view, thereby serves the broader political purpose of ensuring peace and security for all by utilizing psychological insights that can be transformed into a concrete pedagogical method serving to accommodate exemplary narratives to the ingenia of novices. I am proposing that such a method can be recreated by investigating Spinoza's use of the concept of ingenium as this indicates how Spinoza would approach the educational project of ethical formation of novices. Placing focus on the relation between teacher and student, and on how the teacher can accommodate lessons in a way that speaks to the student's ingenium, a Spinozistically conceived education is concerned with utilizing the resources of the imagination in order to gradually strengthen the power of reason over dangerous affects like hatred and fear. Let us look closer at this key aspect that functions by connecting Spinoza's naturalistic psychology with his political theory in a decidedly educational manner.

James (2010) has studied the relation between emotional engagement and the possibility of developing practical and ethical knowledge through the frameworks of Spinoza's psychological theory and his political philosophy. It is important to note that rather than understanding the imagination and human affects as obstacles to conquer in our striving for true knowledge, Spinoza maps out the relation between rationality, imagination, and emotions in order to better understand the dynamic interaction between them. We are not either rational or irrational on Spinoza's account. We are caught between, on the one hand, always striving for reliable knowledge (as reliable knowledge will help us strive for realistic ethical aims that in turn help us persevere in existence), and on the other hand, always being cognitively limited, which is why we need to compensate for this innate limitation by drawing on our imagination (which often deceives us). This is inevitable and it would therefore be very unfortunate if we were to idealize a form of pure reason that antagonizes the impact of emotions in a way that flies in the face of our passionate nature. Spinoza's major complaint against political philosophers is precisely that they tend to ground their theories in a highly idealized understanding of human nature (TP $\left.1[1]^{13}\right)$. Accordingly, it would not be rational

${ }^{13}$ References to the Political Treatise (TP) are to Chapter and section of Spinoza (2016a). 
to act as if we were fully rational when we are in fact not. ${ }^{14,15}$ James claims that this goes to illustrate how philosophical principles must be made to fall within the reach of the imagination in order to be able to shape people's desires and actions $(2010,267)$.

James (2010) starts out from Spinoza's metaphysical supposition about our limited ability to understand the world adequately and applies his ideas about how the imagination can be made to support reason on the example of how different narrative representations of the world can provoke different emotional responses (and how these can be used for ethical and political purposes). Spinoza argues that the best way for humans to begin to perceive the benefits of peaceful coexistence is to arrive at a philosophically sound understanding of themselves and of nature. Because this understanding is exceedingly difficult to attain (due to our innate cognitive limitations), Spinoza proposes the use of collective narratives that can capture the imagination while at the same time leading people towards a relatively stable understanding of how the individual's striving for well-being is conditioned by the stability of the collective (TTP 6[49-50]).

Spinoza uses different examples of narratives to illustrate this. These examples span from narratives that may be used for the purposes of political and social governance to fictions that may offer a framework for developing the ethical understanding of the individual by establishing connections between personal experiences and collective narratives. There are powerful narratives (such as the stories in the Bible) that can captivate many people at once and that can enable them to strive for similar things as a group. These narratives, however, can be exploited for the purpose of passivating vulnerable groups in society; groups that may come to harbor mistrust and unrest which may lead to social and political instability over time. ${ }^{16}$ Other narratives may be easier to mold in accordance with the needs of the individual, but these narratives often lack the ability to capture the imagination of many so as to stabilize the collective.

The task of identifying collective narratives that can speak to many different people in many different contexts is challenged by the fact that each person is differently constituted

\footnotetext{
14 Spinoza addresses this important concern in his Theological Political Treatise (TTP), arguing that the reason we need laws and moral standards to begin with is to compensate for the fact that we are not-nor will we ever be-fully rational:

Now if nature had so constituted men that they desired nothing except what true reason teaches them to desire, then of course a society could exist without laws; in that case it would be completely sufficient to teach men true moral lessons, so that they would do voluntarily, wholeheartedly, and in a manner of a free man, what is really useful. [21] But human nature is not constituted like that at all. It's true that everyone seeks his own advantage - but people want things and judge them useful, not by the dictate of sound reason, but for the most part only from immoderate desire and because they are carried away by affects of mind which take no account of the future and of other things. [22] That's why no society can continue in existence without authority and force, and hence, laws which moderate and restrain men's immoderate desires and unchecked impulses. (TTP 5[20-22], G III/73/27-74)

For further references to places where Spinoza establishes that human nature is not naturally inclined towards reason see TTP 16[7] and the preface to Part 4 of the Ethics (Spinoza 1985a).

15 References to the TTP are to Chapter and section of Spinoza (2016b). References to the non-geometrically ordered passages from the Ethics, as well as references to the TP and the TTP are sometimes supplemented by references to Gebhardt's edition Spinoza Opera (Spinoza 1925) according to the following form: G II/208/25-30= Gebhardt, Vol. 2, page 208, lines 25-30.

16 Michael A. Rosenthal comments on this tension between universality and particularity in exemplary narratives:

What appears to be universal actually reflects some more particular interpretation of experience. The idea that scripture is "revealed" hides its human origins, the source of an exemplar's strength but also of its weakness. It can appeal to a large group of people of diverse interests and ideas. But it can also be placed in service of those divergent interests. (Rosenthal 2002, 244)
} 
affectively. Each person, that is, has a different ingenium $\left(\mathrm{E} 3 \mathrm{p} 31 \mathrm{c}^{17}\right)$. What a person strives for may be understood in terms of a reflection of her affective composition, which, in extension, means that a person's moral motivation is also determined by her ingenium (Steinberg, 2018, 19-23). This entails that different narratives affect different people in different ways, and that different narratives will affect the same people in different ways depending on the situation. At the same time, there is a collective aspect to people's affective composition explained by the fact that people are influenced by one another to the extent that they benefit from similar things, such as friendship and knowledge, and to the extent that they have had common experiences. This entails that not only individuals, but also groups, have an ingenium insofar as they share a common history and experience similar living conditions.

It is no surprise, therefore, that Spinoza's use of the concept of ingenium in his works on political theory (the Theological Political Treatise and the Political Treatise) focuses largely on how to understand, account for, and respond to the ingenium of groups and peoples. One of the consequences that Spinoza's draws from his conclusion that people's general understanding of the world is bound up with their affective experiences (as individuals and as groups) rather than determined solely by reason, is that these experiences need to be addressed and used for pedagogical purposes:

It follows that if someone wants to teach a doctrine to a whole nation - not to mention the whole human race - and wants everyone to understand him in every respect, he is bound to prove his doctrine solely by experience, and for the most part to accommodate his arguments and the definitions of his teachings to the power of understanding of ordinary people, who form the greatest part of the human race. (TTP 5[37])

A major challenge in this is that people's affects are generally not restrained 'by the true knowledge of good and evil insofar as it is true but only insofar as it is considered as an affect' (E4p14c). That is, on Spinoza's account, a person's understanding and behavior is shaped by her affective composition-her ingenium — which, in turn, is externally determined insofar as all people are highly susceptible to external influences. Since an 'affect cannot be restrained or taken away except by an affect opposite to, and stronger than, the affect to be restrained' (E4p7), the imagination needs to be enlisted so that people's experiences and memories can be made to connect with, and strengthen, the power of reason (TTP 5[35-37]).

\section{Exemplarity in Spinoza: Ethics, Politics, and Education}

Returning to the admiration-emulation model of moral education, we are now in a position to see more clearly how Spinoza's use of the concept of ingenium can be a valuable theoretical resource for addressing the problem in the case of Richard Fountain of Doctors Wear Scarlet. My hypothesis was that Richard Fountain fails to act as an effective exemplar because he is not attuned to the ingenia of his subjects. Spinoza can help us explain this in

\footnotetext{
${ }^{17}$ References to the Ethics are abbreviated according to the following standard method: Ethics (E), axiom (a), corollary (c), definition (d) before proposition, demonstration (d) after proposition, lemma (L), proposition (p), postulate (post), preface (pref), scholium (s), explanation (exp). Example: E2p7s =Ethics, part 2, proposition 7 , scholium.
} 
terms of the dynamics of people's affective constitution. If we recall that a person's affects will not be restrained 'by the true knowledge of good and evil insofar as it is true but only insofar as it is considered as an affect' (E4p14c), we see that while Richard Fountain may be argued to exhibit morally exemplary behavior, he is ineffective as an exemplar insofar as he fails to attract the imagination of his subjects. In order to understand what an effective exemplar would look like, it is useful to turn to Spinoza's use of exemplars in his political works. In this context, Spinoza is concerned with exemplars that can appeal to people who are not already on the path to virtue, but whose affective constitution is determined largely by passive affects. ${ }^{18,19}$

In an educational context, it seems reasonable to assume that - to varying degrees-students are not necessarily attracted to what may be described as supremely admirable people. The reason for this being that the identification of morally admirable behavior presupposes a substantial understanding of what is to be judged morally exemplary (Szutta 2019). This kind of judgment is, arguably, the result rather than the starting point of good moral education. In the absence of a developed moral judgment, students may need to become imaginatively engaged with narratives that can enlist their admiration without being perceived as being too far removed from the sociocultural and sociopolitical contexts in which the students operate. This conception of students approximates Spinoza's understanding of 'ordinary people' and so it would seem that Spinoza's conception of how fallible or imperfect exemplars can be used to appeal to the ingenium of groups of people can be productively applied to an educational context (see Dahlbeck and De Lucia Dahlbeck 2020).

The connection Spinoza establishes between ethics, politics, and education corresponds with the tight relation he sets up between the striving for the supreme good of the individual and the purpose of social organization writ large. As sketched out in the previous section, Spinoza appears to blur the distinction between these domains to the degree where it becomes difficult to see exactly where one domain ends and the other begins. This is not done by accident, however, but it is a systematic way of illustrating how ethical well-being is the summum bonum of human existence, and where politics and education-in different ways - are necessary instruments for the attainment of this supreme good. While this may seem overly abstract (and of interest perhaps mainly for the historian of ideas), it is important to pause a moment to consider what the blurring of these distinctions might mean for education in a more contemporary sense. I propose that what Spinoza stands to offer is a more dynamic and less idealistic concept of politics that involves educational endeavors to the extent that education becomes a-broadly conceived-political instrument, geared for refocusing attention on the ethical dimensions of education. That is, education for Spinoza is always (directly or indirectly) aimed at human flourishing (and ethical well-being), but a precondition for human flourishing is political stability and therefore education must enlist powerful exemplary narratives (such as the narrative of the social contract) that can help secure the peace and stability of the state by appealing to the imagination of the students.

\footnotetext{
18 A passive affect, in Spinoza's sense, is succinctly described by Sanem Soyarslan as 'a change in the individual's power, the adequate cause of which lies not wholly in the individual itself, but partly in external things' (Soyarslan 2014, 240n). To be passively affected, then, is to be changed by things that are external to oneself and therefore beyond one's control.

19 Spinoza's exemplarism is typically linked to his posited model of human nature of the free man in the Ethics (E4p66s-E4p77). The free man makes for a perfectly rational human being, according to which the relatively rational person can strive to live better and more ethically. The model of the free man seems to be useful primarily for a person already on the path to virtue, however, and it is therefore of questionable practical use in a broader educational and/or political context (see Dahlbeck and De Lucia Dahlbeck 2020).
} 
The peace and stability of the state is not an end in itself, however, but a means to the end of facilitating the individual's striving for a more sustainable form of ethical well-being. It falls upon the teacher to relate these narratives in a way that is attuned to the ingenia of the novices of education.

The starting point for Spinoza's account of exemplarism in a political setting is that people in general (i.e. 'ordinary people') are far less rationally oriented than they tend to think that they are. That is, we do not exert the kind of control over our emotional responses to forces around us in the world that we often like to think. Also, on Spinoza's account, emotions and affects are highly contagious and so we are much more prone to be influenced by each other (for good or for bad) than we tend to acknowledge. ${ }^{20}$ The upshot of this for an exemplarist moral theory is that the cognitive capacities of an individual will not make for a terribly reliable instrument for securing the emulation of admirable behavior. Instead, exemplarism must account for the human tendency to be moved by passive affects, and to harness the productive aspects of the naturally occurring imitation of affects. While the fact that emotions and affects are highly contagious can often be a problem-as it explains why negative emotions like fear, suspicion, and hatred spread easily-it is also the very thing that enables the efficacy of exemplarism. Insofar as the exemplar (in the form of the teacher and the content related) is attuned to the ingenium of the group addressed, the people of the group will be more readily affected by the emotions displayed. We can never share another person's ingenium fully. We can only ever approximate it insofar as we share common experiences and insofar as we adhere to similar social norms and traditions. Common experiences and common sociopolitical and sociocultural frameworks therefore play an important role for how Spinoza conceives of the effective political exemplar.

In the TTP, Spinoza turns to Moses as an illustration of how an effective exemplar operates in situ. ${ }^{21}$ Spinoza's understanding of Moses is not that of a perfect moral exemplar. It is not on account of his perfect moral wisdom and behavior that Moses can appeal to and successfully govern the Hebrews. It is because he is perfectly attuned to the ingenium of the Hebrew people that he can do this. This ability to adapt to the ingenium of the Hebrew people is due to Moses' powerful imagination rather than to his moral superiority or his power of reasoning.

He also perceived the way that people could best be compelled to obedience. But he did not perceive, and it was not revealed to him, that that way is best - or even that the goal they were aiming at would necessarily follow from the general obedience

\footnotetext{
${ }^{20}$ Spinoza ascribes this tendency to the imitation of affects. Very briefly, the doctrine of the imitation of affects is grounded in what Spinoza calls the association of ideas (E2p18). We are conditioned to react to a thing with either pleasure or displeasure depending on what ideas and experiences we associate it with. Past experiences thereby shape our affective responses to things and people we encounter in our daily lives (E2p18d). The imitation of affects feeds from this and it stipulates that we are more easily affected by things that are like us than we are by things we imagine we have few things in common with (E3p27). To the extent, then, that we identify with another person we will tend to imitate what that person strives for and opposes. In an ethical setting this sets up a complex socioemotional scheme where one person's striving for virtue is strengthened by other people striving for the same thing:

The good which man wants for himself and loves, he will love more constantly if he sees that others love it (by 3p31). So (by 3p31c), he will strive to have others love the same thing. And because this good is common to all (by p36), and all can enjoy it, he will therefore (by the same reason) strive that all may enjoy it. And this striving will be greater, the more he enjoys this good (by 3p37), q.e.d. (E4p37d2)

I have explored the educational implications of Spinoza's doctrine of the imitation of affects in Dahlbeck (2016, Ch. 5).

21 For an insightful take on the exemplarity of Moses in Spinoza's political writings see Rosenthal (2002).
} 
of the people in such a region of the world. So he perceived all these things, not as eternal truths, but at precepts and institutions and he prescribed them as laws of God. That's why he imagined God as a ruler, a lawgiver, a king, as compassionate, just, etc., when all these things are attributes only of human nature, and ought to be removed entirely from the divine nature. (TTP 4[29-30])

From Spinoza's perspective, Moses' understanding of God (and of the laws of God) is clearly not perfect but severely distorted by the limitations of human imagination. This may prevent him from perceiving ethics in terms of eternal philosophical truths, but it enables him to conceive of ethics in terms of moral commands to be obeyed. This, however, is not just a reflection of the fallibility of Moses. It indicates something important that he shares with the ingenium of the majority of the Hebrew people, or so Spinoza claims. Moses' way of leading the Hebrews is perfectly aligned with their past experiences and so it speaks to what is well-known and familiar:

He did not permit these men, accustomed as they were to bondage, to act just as they pleased. For the people could do nothing without being bound at the same time to remember the law, and to carry out commands which depended only on the will of the ruler. For it was not at their own pleasure, but according to a fixed and determinate command of the law, that they were permitted to plow, to sow, to reap. (TTP $5[30])$

Insofar as this seems to lead us away from, rather than closer to, the question of moral exemplarism, it is important to remind that for Spinoza, as we have seen, political stability is an absolute precondition for ethics. ${ }^{22}$ The past experiences of the Hebrews had made it so that '[a]lmost all of them were unsophisticated in their mentality and weakened by wretched bondage' and because of this, Spinoza asserts, 'the sovereignty had to remain in the hands of one person only, who could command the others, compel them by force, and finally, who would prescribe laws and afterward interpret them' (TTP 5[27]). Had their past experiences been different, however, they would respond better to a different kind of leadership. And so, good governance is always relative to the ingenia of peoples. And a good leader-much like a good teacher-is characterized by the ability to correctly read

\footnotetext{
${ }^{22}$ In the TP, Spinoza explains the tight connection and reciprocity between the right of the individual to strive for a virtuous life (which for Spinoza is the same as a life guided by reason) and the need for stability and security in civic life. He writes:

$[R]$ eason teaches us without qualification to seek peace, which certainly can't be obtained unless the common laws of the Commonwealth are observed without violation. So, the more a man is led by reason, i.e. (by ii, 11), the more free he is, the more steadfastly he will observe the laws of the Commonwealth and carry out the commands of the supreme power to which he is subject. (TP 3[6], G III/286/17-25)

As early as in the Treatise on the Emendation of the Intellect (TIE) Spinoza (1985b) affirms the importance of adapting teachings of ethics to 'the power of understanding of ordinary people' so as to ensure that the striving for virtue is not hampered by civil unrest. Accordingly, he writes that 'we can gain a considerable advantage, if we yield as much to their understanding as we can. In this way, they will give a favorable hearing to the truth' (TIE §17). According to Sangiacomo (2019), Spinoza did not, however, assign the positive role to social cooperation in the TIE that he would come to do in his later texts. Sangiacomo helpfully sketches Spinoza's development from his early endorsement of what Sangiacomo calls 'the epistemic self-sufficiency of the mind' in the TIE to his later acceptance of the importance of enlisting sociopolitical forces for the purpose of ethical and rational fostering in his political works. Spinoza's use of the concept of ingenium may be taken to reflect this gradual turn towards a more positive understanding of the role of social cooperation as a crucial mechanism for working toward the strengthening of collective forms of use of reason.
} 
(and adapt his or her teachings to) the ingenium of the subjects. Reconfiguring the political leader of Moses into a Spinozistically conceived teacher, then, we find that a teacher that is equipped with a powerful imagination — and that is thereby able to adjust collective narratives so as to appeal to the ingenia of the students-is perhaps more adept at teaching than a supremely wise teacher (who may be too far removed from the ingenia of his or her students to be able to influence them).

Unsurprisingly, then, a stable and secure political community is also a necessary precondition for good education (as indicated above). As Christophe Miqueu puts it: 'The political dimension of education is central here. The freedom to philosophize can only exist if the republic itself is reformed. This is undoubtedly one of the central points of Spinoza's republicanism' $(2018,5)$. To sum up Spinoza's views on the efficacy of exemplars (whether they be conceived in terms of political leaders or teachers of children and students), we may conclude that in order to be of practical relevance exemplars should: (1) be attuned to the ingenium of the subjects; (2) make use of collective narratives that appeal to the imagination of the subjects; and, (3) not focus narrowly on the acquisitions of virtues without attending first to the sociopolitical stability of the collective. The role of the teacher in this set-up, is to navigate in the pedagogical triangle between the student and the content, acting at once as a pedagogical and ethical exemplar (by living in a way that accords with his or her teachings) and as a person in charge of the didactical exemplarity necessary for being able to identify and relate narratives that are attuned to the ingenia of the students, while leading them into the world and thus broadening the scope of their affective composition.

\section{Some Preliminary Consequences for Educational Theory}

In the final section of this article, I wish to highlight three preliminary consequences for educational theory as well as say something about how the concept of ingenium may be conceived in a practical pedagogical setting. These are clearly interrelated but they illuminate different key aspects that - when taken together - add to a fuller understanding of the challenges facing exemplarism in education and that can help us address the shortcomings of the admiration-emulation model.

(1) The concept of ingenium can help us focus on the affective compatibility of teachers and students (and both in relation to the content), and on developing a more robust understanding of the conditions for why some pedagogical relations work better than others do. Rather than focusing only on diagnosing the ingenium of the student, however, this investigation would need to understand the ingenium of the student always in relation to the ingenium of the teacher, so as to account for the sociability of emotions and the sociocultural and sociopolitical conditions for education in general, and for moral education in particular.

(2) Spinoza's use of the concept of ingenium helps us see that narratives of moral exemplars, in an educational context, must appeal to the imagination of the students in order to work. Following Steinberg's (2018) 'Principle of Accommodation' thesis, Spinoza's political psychology can help explain why ethical advice and moral guidelines need to be accommodated to the ingenia of ordinary-imaginatively motivated-people in order to be effective. This, of course, raises important questions about the justification for willful manipulation of students' emotional responses. 
While these questions lie beyond the scope of this article, ${ }^{23}$ it is important to note that the reason we need civic institutions to begin with, for Spinoza, is to compensate for our innate lack of power of reason (TTP 5[20-22]). Whether we like it or not, we need to account for this lack, lest we end up striving for ethico-political ideals that will prove utterly unrealistic and therefore unattainable (see TP 1[1]). Ideals and narratives that engage people's imagination are, on Spinoza's account, therefore the only ones that will move them towards becoming more ethical.

(3) In order to appeal to the imagination of students, moral exemplars must be affectively relatable rather than supremely admirable persons (Dahlbeck and De Lucia Dahlbeck 2020). This means that sometimes less than supremely moral persons are more effective exemplars than supremely moral persons (as is the case with the figure of Moses in Spinoza's political texts). Hence, fallibility can be a necessary pedagogical aspect of an effective exemplar, while infallibility can be perceived as alienating and thereby become an obstacle rather than an asset to education. This entails that teachers must pay close attention to the narratives they use and the way they present themselves. On the one hand, they need to be attuned to the affective composition of the student group, but on the other hand, they also need to make sure not to allow passive affects to completely dominate the judgment and motivation of the students, leading them astray from the path to virtue altogether. The teacher in this conception faces the dual challenge of being a pedagogical and ethical exemplar and of selecting exemplary narratives that can entice students to begin their transformation into moral persons.

Taken together, these three preliminary consequences for educational theory are meant to point us in the direction of a productive discussion on the challenges and educational promise of moral exemplarism. This article should not be taken as a proposal for a new program of moral education, but as a more humble suggestion for how the concept of ingenium (and especially Spinoza's use of it) can be turned into a helpfulalbeit perhaps counterintuitive-asset for how we might conceptualize the dynamics of exemplarism in an educational setting. This appears important, not least because while moral philosophy may benefit from conceptual clarity and analytical tidiness, pedagogical practice and theory may not necessarily benefit from an account of exemplarism that shies away from the inherent messiness of the interplay between emotions and reason or the tension between ethical flourishing and sociopolitical stability. Insofar as the aim is a more realistic account of moral exemplarism in education, then, I propose that the neglected pedagogical concept of ingenium can offer an interesting starting-point for discussing how the educational cultivation of virtue interconnects with, and is conditioned by, configurations of social emotions and collective norms. While these complex interpersonal processes are unlikely to ever be exhaustively accounted for, acknowledging their importance for the dynamics of pedagogical relations appears to be a necessary precondition for the construction of a functioning theoretical framework for exemplarism in education.

In order to clarify how Spinoza's concept of ingenium can play into concrete pedagogical situations (and in extension add to a theoretical framework for exemplarism in education) it is helpful to insert it into the scheme of a pedagogical triangle. The pedagogical triangle is a triangle connecting the student (at the lower left end) to the teacher (at the top

\footnotetext{
${ }^{23}$ I have explored questions about the justification for student manipulation and Illusionism from the perspective of Spinoza's philosophy in Dahlbeck (2020).
} 
end) and to the content (at the lower right end). From the teacher at the top of the triangle is a dotted vertical line with an arrow pointing to the bottom horizontal line connecting the student to the content. Norm Friesen and Richard Osguthorpe explains the pedagogical triangle as follows:

Student and content are linked through learning, study and work; teacher and content are linked both through preparation and instruction. The student and teacher, finally, are connected through the much-studied student-teacher relationship, or what is known in the German context as the "pedagogical relation" [...]. The dotted vertical line and arrow in the middle of the triangle indicates the focus of the teacher on affecting the relationship of student to content - both through his or her direct relation to the student and to the content. In the pedagogical situation, the teacher intends to change the relation of student to content from unnecessary uncertainty or confusion to clarity and confidence. (Friesen and Osguthorpe 2018, p. 257).

Accommodating his or her teachings to the student's ingenium is what allows the exemplary teacher to effectively influence the relation between student and content from one marked by general confusion to one marked by the joint striving for clarity. For this to work, however, the teacher's and the student's ingenium must be sufficiently compatible lest their pedagogical relation deteriorates. This, as we have seen, requires self-examination on the part of the teacher, and it requires both pedagogical and didactical exemplarity sufficiently accommodated to the ingenium of the student. As Spinoza illustrates, however, the pedagogical triangle is not insulated from external things such as social emotions or collective norms, but rather positioned so as to draw on these various external forces when refocusing the educational transformation of the student in the direction of a more ethical life. It is the exemplary teacher's task to enlist collective narratives that can help foster the motivation and imagination of the student in this setting. An important aspect of this task is to enlist narratives that display sufficiently admirable behavior without being perceived as too far removed from the actual living conditions and the ingenium of the student.

Acknowledgements For their helpful comments on earlier drafts of this article, the author would like to thank Justin Steinberg, Andreas Hellerstedt, Hanna Sjögren, and Morten Korsgaard. Open access funding provided by Malmö University.

Open Access This article is licensed under a Creative Commons Attribution 4.0 International License, which permits use, sharing, adaptation, distribution and reproduction in any medium or format, as long as you give appropriate credit to the original author(s) and the source, provide a link to the Creative Commons licence, and indicate if changes were made. The images or other third party material in this article are included in the article's Creative Commons licence, unless indicated otherwise in a credit line to the material. If material is not included in the article's Creative Commons licence and your intended use is not permitted by statutory regulation or exceeds the permitted use, you will need to obtain permission directly from the copyright holder. To view a copy of this licence, visit http://creativecommons.org/licenses/by/4.0/.

\section{References}

Croce, M. 2020. Moral exemplars in education: A liberal account. Ethics and Education 15 (2): 186-199.

Dahlbeck, J. 2016. Spinoza and education: Freedom, understanding and empowerment. London: Routledge. Dahlbeck, J. 2017. A Spinozistic model of moral education. Studies in Philosophy and Education 36 (5): 533-550.

Dahlbeck, J. 2020. Education, illusions and valuable fictions. Journal of Philosophy of Education 54 (1): 214-234. 
Dahlbeck, J., and M. De Lucia Dahlbeck. 2020. The moral fallibility of Spinoza's exemplars: exploring the educational value of imperfect models of human behavior. Ethics and Education 15 (2): 260-274.

Della Rocca, M. 1995. Spinoza's metaphysical psychology. In The Cambridge companion to Spinoza, ed. D. Garrett, 192-266. Cambridge: Cambridge University Press.

Friesen, N., and R. Osguthorpe. 2018. Tact and the pedagogical triangle: The authenticity of teachers in relation. Teaching and Teacher Education 70: 255-264.

Hansen, D.T. 2001. Exploring the moral heart of teaching: Toward a Teacher's Creed. New York: Teachers College Press.

Hellerstedt, A. 2019. From ingenium to virtus: The cultivation of talent in seventeenth century dissertations from Uppsala University. Nordic Journal of Educational History 6 (1): 71-93.

Hidalgo-Serna, E. 1983. 'Ingenium' and rhetoric in the work of Vives, translated by L. Ballew \& H. Wilson. Philosophy \& Rhetoric 16 (4): 228-241.

James, S. 2010. Narrative as the means to freedom: Spinoza on the uses of imagination. In Spinoza's 'theological-political treatise': A critical guide, ed. Y.Y. Melamed and M.A. Rosenthal, 250-267. Cambridge: Cambridge University Press.

Korsgaard, M.T. 2019. Exploring the role of exemplarity in education: Two dimensions of the teacher's task. Ethics and Education 14 (3): 271-284.

Kotsonis, A. 2020. On the limitations of moral exemplarism: Socio-cultural values and gender. Ethical Theory and Moral Practice 23 (1): 223-235.

LeBuffe, M. 2010. From bondage to freedom: Spinoza on human excellence. Oxford: Oxford University Press.

Masschelein, J., and M. Simons. 2013. Defence of the school: A public issue. Leuven: Education, Culture and Society Publishers.

Miqueu, C. 2018. Spinoza on civic education. In Encyclopedia of educational philosophy and theory, ed. M.A. Peters, 1-5. Singapore: Springer.

Noreña, C.G. 1970. Juan Luis Vives. The Hague: Springer.

Raven, S. 2019[1960]. Doctors Wear Scarlet. Richmond, VA: Valancourt Books.

Rosenthal, M.A. 2002. Why Spinoza chose the Hebrews: the exemplary function of prophecy in the Theological-Political Treatise. In Jewish themes in Spinoza's philosophy, ed. H.M. Ravven and L.E. Goodman, 225-260. New York: SUNY Press.

Sangiacomo, A. 2019. Spinoza on reason, passions, and the supreme good. Oxford: Oxford University Press.

Soyarslan, S. 2014. From ordinary life to blessedness: The power of intuitive knowledge in Spinoza's Ethics. In Essays on Spinoza's ethical theory, ed. M.J. Kisner and A. Youpa, 236-257. Cambridge: Cambridge University Press.

Spinoza, B. 1925. Spinoza Opera, vol. 4. Heidelberg: Carl Winter.

Spinoza, B. 1985a. Ethics: Demonstrated in geometric order and divided into five parts (Ethics). In The collected works of Spinoza vol. I, translated and edited by E. Curley, 408-617. Princeton: Princeton University Press.

Spinoza, B. 1985b. Treatise on the emendation of the intellect (TIE). In The collected works of Spinoza vol. I, translated and edited by E. Curley, 3-45. Princeton: Princeton University Press.

Spinoza, B. 2016a. Political treatise (TP). In The collected works of Spinoza vol. II, translated and edited by E. Curley, 503-604. Princeton: Princeton University Press.

Spinoza, B. 2016b. Theological political treatise (TTP). In The collected works of Spinoza vol. II, translated and edited by E. Curley, 65-354. Princeton: Princeton University Press.

Steinberg, J. 2018. Spinoza's political psychology: The taming of fortune and fear. Cambridge: Cambridge University Press.

Steinberg, J. 2020. Politics as a model of pedagogy in Spinoza. Ethics and Education 15 (2): 158-172.

Szutta, N. 2019. Exemplarist moral theory-Some pros and cons. Journal of Moral Education 48 (3): 280-290.

Vives, J.L. 1913. Vives: On education [De Tradendis Disciplinis], translated by F. Watson. Cambridge: Cambridge University Press.

Zagzebski, L. 2015. Admiration and the admirable. Proceedings of the Aristotelian Society: Supplementary 9 (1): 205-221.

Zagzebski, L. 2017. Exemplarist moral theory. Oxford: Oxford University Press.

Publisher's Note Springer Nature remains neutral with regard to jurisdictional claims in published maps and institutional affiliations. 